\title{
Epidural anaesthesia and myomectomy-associated blood loss - a prospective randomised controlled study
}

\author{
Mohamed Farghali ${ }^{1}$ (i) , Abdelrady S. Ibrahim², Waleed S. Farrag ${ }^{1}$ \\ ${ }^{1}$ Faculty of Medicine, Ain Shams University, Abbassia, Egypt \\ ${ }^{2}$ Faculty of Medicine, Assiut University Hospital, Assiut University, Assiut, Egypt
}

\begin{abstract}
Objectives: The management of anaesthesia for patients with large myomas is particularly important due to disruption of hemodynamic as a result of massive haemorrhage, the prolonged duration of surgery and requirement for additional interventions. This study evaluated the effect of anaesthetic technique on blood loss in patients undergoing myomectomy due to large fibroid uterus.

Material and methods: A total of 156 patients that underwent myomectomy were randomized into two equal groups according to the type of anaesthesia: Epidural anaesthesia group and General anaesthesia group. The volume of blood loss and blood products transfusion was reviewed for each patient.

Results: The intraoperative blood loss and need for blood transfusion were significantly higher in general anaesthesia group $(p<0.001)$. The mean hematocrit change was $2.5 \pm 1.5$ vs $3.7 \pm 2.9 \%(p=0.001)$ for both groups.

Conclusions: In the myomectomy planning of women with a large fibroid uterus, the team of gynecologists and anaesthesiologists should take care to choose the most optimal technique for anaesthesia.

Key words: epidural anaesthesia; general anaesthesia; myomectomy; blood loss
\end{abstract}

Ginekologia Polska 2022; 93, 11: 861-866

\section{INTRODUCTION}

Uterine leiomyomas are the most common benign tumor of the reproductive system in women of childbearing age [1]. A hysterectomy is the optimum treatment for symptomatic fibroids. However, for patients who seek future pregnancy or preservation of the uterus, myomectomy is a popular option [2]. Abdominal fibroid enucleation is often preferred over laparoscopic myomectomy in the cases of large and multiple leiomyomas [3]. Intraoperative bleeding requiring blood transfusion is the most common complication of an abdominal myomectomy [4] and, when uncontrolled, may require a hysterectomy [5].

The amount of blood transfusion in open myomectomy depends on the size of the uterus and the number and site of fibroids [3]. The overall rate of a blood transfusion during abdominal myomectomy is 13.5 to $58.2 \%$ [6], with an unpredictable rate of hysterectomy about $2 \%$ after uncontrolled bleeding $[2,6]$. Therefore, during myomectomy, effective measures to reduce blood loss are desirable [2].

A number of medical and surgical techniques have been attempted to significantly reduce bleeding during myomectomy. This includes peri-operative vaginal misoprostol and dinoprostone, intraoperative vasopressin, intrauterine bupivacaine and epinephrine, intravenous tranexamic acid and ascorbic acid, gelatin-thrombin matrix, loop ligation of thepseudo-capsuleoftheleiomyoma, and by using afoleycatheter as a cervical tourniquet [7]. However, each technique has its limitations; therefore, blood loss control remains the main goal for both anaesthesiologists and gynaecologists [8].

To our knowledge, no published study had systematically assessed the effectiveness of epidural anaesthesia and myomectomy. Hypotensive technique during anaesthesia allowed for a significant reduction in blood loss without compromising the perfusion of vital organs [9], thereby 
reducing transfusion requirements and reducing the risk of allogeneic transfusion [10].

This study was conducted to determine the amount of blood loss during surgery and to find the optimum perioperative anaesthetic method in patients undergoing myomectomy for treatment of large fibroids. The primary outcome measure was estimated blood loss during myomectomy. The secondary outcome measures were the amount of blood transfusions during surgery, intraoperative recourse to hysterectomy and post-operative change in haematocrit.

\section{MATERIAL AND METHODS}

\section{Study design}

This prospective randomized clinical study was conducted between June 2014 and May 2019 at Sabah Maternity Hospital - a tertiary health facility in Kuwait. The Sabah Maternity Hospital has 320 beds, with an annual rate of about 4000 gynaecologic admissions.

\section{Ethical consideration}

The study protocol was approved by the ethical review committee of the Sabah Maternity Hospital, Kuwait before commencement of the study and it was post-registered at ClinicalTrials.gov (NCT04629573). Written and informed consent was obtained from all patients after thorough explanations about study purpose, design, and procedures to each patient.

\section{Eligibility criteria}

Patients over 18 years of age, American Society of Anesthesiologist (ASA) I and II, undergoing myomectomy to treat large uterine leiomyomas (with a diameter of at least $10 \mathrm{~cm}$ as diagnosed by transvaginal ultrasonography) were included in this study. Exclusion criteria: Patients with a history of previous uterine surgery (myomectomy, caesarean delivery), coagulopathy or other bleeding diathesis and severe anaemia ( $\mathrm{Hb}$ under $7.0 \mathrm{~g} / \mathrm{dL}$ ) were excluded from the study.

\section{Study groups}

A total of 156 patients were randomized into two equal groups according to the type of anaesthesia, 78 patients in each group: Epidural anesthesia group (Group I) and General anesthesia group (Group II).

\section{Randomization and blinding}

The management protocol for each group was prepared by the researchers before the study began and sealed one protocol per envelope with a computer-generated number assigned prior to study initiation. Randomization was performed by selecting sequentially numbered envelopes and opening them before induction of anaesthesia by the anaesthetist and managing the participant according to the attached protocol. The study will not be double-blind, as healthcare professionals and patients cannot afford to ignore a strategy to which the woman is allocated.

\section{Interventions \\ Anaesthesia procedures:}

Upon arrival to the operative theatre, an 18- gauge IV catheter was inserted and $500 \mathrm{~mL}$ of $\mathrm{NaCl}(0.9 \%)$ was administered, $1 \mathrm{mg}$ of intravenous midazolam was given as premedication. Patients were monitored by ECG, pulse oximetry and non-invasive blood pressure regularly every five minutes.

Lumbar epidural. Epidural procedures were performed by attending anaesthesiologists who performed at least 50 epidural procedures during their studies The Patient was placed in a sitting position, the skin in the lumbar region was cleaned and sterilization procedures were followed throughout the procedure. The skin and subcutaneous tissue were infiltrated with $2 \mathrm{~mL}$ of $1 \%$ lidocaine at the site of epidural placement (L2-3 or L3-4 interspace). The lumbar epidural space was localised, using a midline approach with an 18-gauge Tuohy epidural needle by loss of resistance technique with $2 \mathrm{~mL}$ of saline, 20-gauge epidural catheter was inserted in each patient. An initial bolus dose of $20 \mathrm{~mL}$ bupivacaine $0.5 \%$ plus 100 mcg Fentanyl was given through the epidural catheter, followed by continuous infusion of bupivacaine $0.5 \%$ plus $1 \mathrm{mcg} / \mathrm{mL}$ Fentanyl $(3-5 \mathrm{~mL} / \mathrm{h}$ ).

General anaesthesia. Anaesthesia was started with IV $1 \mu \mathrm{g} / \mathrm{kg}$ fentanyl, $2 \mathrm{mg} / \mathrm{kg}$ propofol and $0.15 \mathrm{mg} / \mathrm{kg}$ cisatracurium to facilitate endotracheal intubation. After tracheal intubation, anaesthesia was maintained with sevoflurane in $\mathrm{O} 2$ and air ( $\mathrm{FiO} 2$ of 0.5 ), and intravenous infusion of $1 \mu \mathrm{g} / \mathrm{kg} / \mathrm{min}$ cisatracurium and $0.5 \mu \mathrm{g} / \mathrm{kg} / \mathrm{h}$ fentanyl. Volume-Controlled ventilation was performed in all patients. Cisatracurium and fentanyl infusion was discontinued at the end of surgery, neuromuscular blockade was reversed, and the patient was extubated and send to post-anaesthesia care unit.

Myomectomy. Abdominal myomectomy was performed using standard conventional techniques. One of the surgeons oversaw all operations. The myomectomy was performed by excision of uterine fibroids and closing the uterine defect in several layers. The use of electrical devices, type of suture, and adhesion barriers were at the surgeon's discretion.

\section{Data collection}

All participants had standard preoperative evaluations including pelvic ultrasound for the size, number and site of leiomyomas. T2-weighted MRI imaging of leiomyoma was a more precise method for measuring leiomyoma volume [11]. Age, parity, body mass index, surgical history, number of previous caesarean sections, indication of myomectomy, 
intraoperative anaesthetic management, ASA classification, pre and postoperative $\mathrm{Hgb}$ and $\mathrm{Hct}$ values, number of fibroids, fibroid dimension and location, suture type, number of layers of closure, concomitant procedures, duration of operation, intraoperative complications.

Outcome measures. The primary outcome was estimated intraoperative blood loss. Intraoperative blood loss was estimated by measuring the volume of blood in suction bottle; other losses were calculated using the gravimetric methods by scanning the pre-weighted abdominal towels and repeating the measurement with a weight difference of 1 gram equal to $1 \mathrm{~mL}$ of blood. Secondary outcomes include need for blood transfusions, need for hysterectomy and total blood loss calculations.

Blood loss calculations. The patient's estimated blood volume (EBV) using the Nadler equation [12]:

$E B V(L)=0.3561 \times$ height $(m) 3+0.03308 \times$ weight $(\mathrm{kg})+0.1833$ (for female)

The amount of intra and post-operative blood loss (TBL) was determined by a comprehensive method that is widely used to measure blood loss perioperatively [13]:

$T B L(L)=E B V(L) \times($ preoperative Hct - postoperative Hct $) /$ /average Hct

Average Hct is the average of haematocrit before and after surgery. In our study, Postoperative Hct was defined as Hct on the day three after myomectomy. To reduce the risk of haemodilution at the expense of blood loss, our patients didn't receive more than $2000 \mathrm{~mL}$ of IV fluid intra or post-operative.

Blood transfusions. Blood transfusion was initiated when the maximum calculated allowable blood loss (transfusion trigger) was exceeded. Ttransfusion of blood and blood products was also initiated with signs of cardiovascular instability or inadequate perfusion or oxygenation. In addition, fresh-frozen plasma (unit), tranexamic acid, human fibrinogen concentrates, crystalloid $(\mathrm{mL})$, and colloid $(\mathrm{mL})$ transfusions were also reviewed.

Sample size calculation. The sample size was calculated by Epi Info software Version 7.2 for Windows. Based on previous study [14], if the standard deviation of blood loss is $1721 \mathrm{~mL}$, this study should consist of 73 patients in each group (sample size), to achieve a power of $95 \%$ and $5 \%$ of significance level (two sided) and to detect a true difference in means between the test and the reference group of $964 \mathrm{~mL}$. Ten patients were added to the sample to compensate for dropouts.

\section{Statistical analysis}

SPSS for Windows 23.0 statistical program (IBM Corp., Armonk, NY, US) was used for data analysis. Continuous variables were represented as median (minimum-maximum) and categorical variables were expressed as frequencies and percentages. Pairwise comparisons were performed using the Mann-Whitney $\mathrm{U}$ test. Chi-square test was used to compare the categorical variables. $\mathrm{P}<0.05$ value was considered significant.

\section{RESULTS}

A total of 202 women were selected for the eligibility criteria within the study. Then, 156 women of the total selected were participated in our study, 78 in each group as show in consort flow diagram.

The mean age of the participants was $39.15 \pm 4.14$ (range, 22-45) years; 66 (42.3\%) were nulliparous, and 94 (60.2\%) had no children. Common symptoms were excessive and or prolonged menstruation ( $n=61 ; 39.1 \%)$, abdominal pain ( $n=25 ; 16 \%)$, inability to conceive $(n=33 ; 21.15 \%)$, mechanical complaints $(n=31 ; 19.87 \%)$ and $6(3.8 \%)$ had other symptoms (Tab. 1).

Both treatment groups were similar with no statistically significant difference in demographic data and preoperative Hb level (Tab. 1). However, the treatment groups differed in characteristics of the fibroids (size, type, volume and numbers), due to lack of stratification of patients according to the size of the myomas. The mean diameter of the largest fibroid was significantly higher in women allocated to group I (Epidural anesthesia) than women allocated to group II (general anesthesia) $14.5 \pm 2.3$ vs $11.7 \pm 1.6 \mathrm{~cm} ; p=0.035$; $95 \% \mathrm{Cl} 0.1-2.0)$. Other characteristics of the fibroids at baseline such as type (subserous, interstitial and submucous), volume of the uterus and the leiomyoma volume planned for excision did not reveal a significant difference (Tab. 2).

Table 3 showed that group II participants recorded higher values in mean intraoperative blood loss [984 \pm 345 vs $745 \pm 289 \mathrm{~mL},(\mathrm{p}=<0.001)]$ and blood products transfusion including PRBCs, FFP and Platelets [48 (61. 53\%) vs $29(37.17 \%),(p=0.008)]$ than group I. Blood transfusions were performed on one patient (1.2\%) in group I, and three patients (3.8\%) in group II postoperative. In group II (under general anaesthesia), four patients and in group I, two patients (under epidural anaesthesia but subsequently converted to general anaesthesia) were subjected to hysterectomy.

The mean preoperative haematocrit was $31.8 \pm 3.6$ vs $31.9 \pm 4.2 \%(p=0.87)$, the mean post-operative haematocrit was $27.4 \pm 2.1$ vs $24.01 \pm 1.3 \%(p=<0.001)$, and the mean haematocrit change was $4.4 \pm 1.5$ vs $7.8 \pm 1.9 \%$ ( $p=0.03$ ) for groups I and II, respectively (Fig. 1). Of the 40 patients who received intraoperative blood transfusion in both groups (group I 15 and group II 25), the change in haematocrit between group I and group II were in the range of $2-10.5 \%$ and this was statistically significant. 
Table 1. Demographic and clinical data of the two studied groups

\begin{tabular}{|l|c|c|c|}
\hline Variables & $\begin{array}{c}\text { Epidural } \\
\text { Anesthesia } \\
(\mathbf{n = 7 8})\end{array}$ & $\begin{array}{c}\text { General } \\
\text { Anesthesia } \\
(\mathbf{n = 7 8 )}\end{array}$ & p value \\
\hline Age (years) & $38.2 \pm 4.9$ & $39.4 \pm 3.8$ & 0.165 \\
\hline Parity & $1(0-3)$ & $2(0-5)$ & 0.128 \\
\hline BMl (kg/m $\left.{ }^{2}\right)$ & 25.2 & 25.8 & 0.439 \\
\hline Hemoglobin (mg/dL) & $(19.6-36.7)$ & $(20.2-38.7)$ & \\
\hline Indication for surgery & $9.8 \pm 1.6$ & $9.5 \pm 1.3$ & 0.722 \\
\hline - Heavy menstrual & & & \\
\hline bleeding & 29 & 32 & \\
\hline - Abdominal pain & 15 & 10 & 0.593 \\
\hline Sub fertility & 16 & 17 & \\
\hline - Mechanical complaints & 13 & 18 & \\
\hline - Others & 5 & 1 & \\
\hline Comorbidity & & & \\
\hline- Hypertension & 12 & 10 & \\
\hline - Diabetes mellitus & 10 & 7 & 0.872 \\
\hline - Hypercholesterolemia & 15 & 20 & \\
\hline - Hypothyroidism & 19 & 21 & \\
\hline - Cardiovascular accidents & 2 & 1 & \\
\hline Previous abdominal surgery & $18(23)$ & $12(15.3)$ & 0.285 \\
\hline
\end{tabular}

Qualitative data were described using numbers and percent while normally quantitative data were expressed in Mean \pm SD and abnormally distributed data were expressed in median (Min-Max.); ${ }^{*}$ - Significant p value $<0.05$; BMI — Body mass index

\begin{tabular}{|c|c|c|c|}
\hline Variables & $\begin{array}{c}\text { Epidural } \\
\text { Anesthesia } \\
(n=78)\end{array}$ & $\begin{array}{c}\text { General } \\
\text { Anesthesia } \\
(n=78)\end{array}$ & $p$ value \\
\hline $\begin{array}{l}\text { Number of Fibroids } \\
\text { - More than } 5 \\
\text { - Less than } 5\end{array}$ & $\begin{array}{l}19 \\
59\end{array}$ & $\begin{array}{l}16 \\
62\end{array}$ & 0.243 \\
\hline $\begin{array}{l}\text { Size of Fibroid } \\
\text { - } \text { Aggregate weight }(\mathrm{g}) \\
\text { - } \quad \text { Largest diameter }(\mathrm{cm}) \\
\text { - }\end{array}$ & $\begin{array}{c}364(80-877) \\
16.8(11.5-20.2) \\
112(78-145)\end{array}$ & $\begin{array}{c}322(92-795) \\
16.1(10.2-19.4) \\
96(71-128)\end{array}$ & 0.812 \\
\hline $\begin{array}{l}\text { Fibroid location } \\
\text { - Subserous } \\
\text { - Interstitial } \\
\text { - Submucous }\end{array}$ & $\begin{array}{l}15(19.23 \%) \\
34(43.58 \%) \\
29(37.17 \%)\end{array}$ & $\begin{array}{c}18(23 \%) \\
27(34.62 \%) \\
33(42.3 \%)\end{array}$ & 0.061 \\
\hline $\begin{array}{l}\text { Layers of closure } \\
\cdot \quad 2 \text { layers } \\
\text { - } 3 \text { layers }\end{array}$ & $\begin{array}{l}22(28.2 \%) \\
56(77.8 \%)\end{array}$ & $\begin{array}{l}27(34.62 \%) \\
51(65.38 \%)\end{array}$ & 0.853 \\
\hline $\begin{array}{l}\text { Associate surgery } \\
\text { - Ovarian cystectomy } \\
\text { - Oophorectomy } \\
\text { - Adhesolysis } \\
\text { - Endometriosis } \\
\text { (excision or ablation) }\end{array}$ & $\begin{array}{l}6 \\
2 \\
4 \\
5\end{array}$ & $\begin{array}{l}8 \\
1 \\
7 \\
7\end{array}$ & 0.653 \\
\hline $\begin{array}{l}\text { Suture type } \\
\text { - Vicryl } \\
\text { - PDS }\end{array}$ & $\begin{array}{c}70 \\
8\end{array}$ & $\begin{array}{c}70 \\
8\end{array}$ & 0.402 \\
\hline Uterine cavity opened & $18(23 \%)$ & $12(115.3 \%)$ & 0.054 \\
\hline
\end{tabular}

Qualitative data were described using numbers and percent while normally quantitative data were expressed in Mean \pm SD and abnormally distributed data were expressed in median (Min-Max.). ${ }^{*}$ - Significant $p$ value $<0.05$

\begin{tabular}{l|c|c|c|}
\hline \multicolumn{4}{|c|}{ Table 3. Perioperative outcomes of the two studied groups } \\
\hline Variables & $\begin{array}{c}\text { Epidural } \\
\text { Anesthesia } \\
(\mathbf{n}=\mathbf{7 8})\end{array}$ & $\begin{array}{c}\text { General } \\
\text { Anesthesia } \\
\text { (n= 78) }\end{array}$ & p value \\
\hline Operative time (min) & $101 \pm 0.693$ & $106 \pm 1.525$ & 0.167 \\
\hline Estimate blood loss (mL) & $745 \pm 289$ & $984 \pm 345$ & $<0.001^{*}$ \\
\hline $\begin{array}{l}\text { Blood products transfusion } \\
\text { - RBCs }\end{array}$ & $15(19.23 \%)$ & $25(32 \%)$ & \\
- Fresh Frozen plasma & $11(14.1 \%)$ & $19(24.35 \%)$ & 0.008 \\
- Platelets & $3(3.84 \%)$ & $4(5.12 \%)$ & \\
\hline $\begin{array}{l}\text { Need for hysterectomy } \\
\text { Postoperative Complications }\end{array}$ & $2(2.56 \%)$ & $4(5.12 \%)$ & 0.523 \\
\hline $\begin{array}{l}\text { - ileus } \\
\text { - DVT or PE }\end{array}$ & 8 & 9 & \\
\hline $\begin{array}{l}\text { Infection or Fever } \\
\text { - wound infection }\end{array}$ & 1 & 1 & 0.204 \\
\hline Hospital stay (Less than 2 days) & 46 & 40 & $0.004^{*}$
\end{tabular}

Qualitative data were described using numbers and percent while normally quantitative data were expressed in Mean \pm SD and abnormally distributed data were expressed in median (Min-Max.); ${ }^{*}$ - Significant $p$ value $<0.05 . \mathrm{RBC} s-$ Red Blood Cell; DVT — Deep Venous Thrombosis; PE — Pulmonary Embolism

\section{DISCUSSION}

Myomectomy can increase the morbidities and the rate of mortality [15], especially when hysterectomy is performed [16]. Intraoperative complications, such as DIC, fluid overload, ARDS, and hemodynamic disturbances that may necessitate blood transfusion may threaten the patient health [17]. Therefore, anaesthetic management in these patients must be well-planned.

General anaesthesia has been reported to be less effective in reducing blood loss in myomectomy compared with epidural anaesthesia. Our study showed that the mean of intraoperative blood loss, blood transfusion rate and number of transfused blood units were higher (statistically significant) among group II (patients who underwent general anaesthesia) compared to group I (those who underwent epidural anaesthesia). However, change in haematocrit level after myomectomy and blood transfusion rate were more pronounced in the group under general anaesthesia. In this study, the mean blood loss in group under epidural anaesthesia was greater than in previous reports [18-20]. Systematic reviews have shown that these studies had lower amount of blood loss due to decreased uterine size to < than 24 weeks [20], $8.7 \pm 4.6$ weeks [19] and $15.7 \pm 2.6$ weeks [18] compared with $18.50 \pm 4.72$ weeks in this study. Our study showed increase in blood loss during myomectomy because blood loss is proportionate to the size of the uterus. The number of fibroids was associated with increase in blood loss, which explains the lower bleeding amount in the Turkish study with the average number of leiomyomas of $5.5 \pm 1$ [18] compared with $8.25 \pm 3.56$ in this study. The calculation of blood loss during abdominal myomectomy remains paramount. The studies in Turkey [18] 


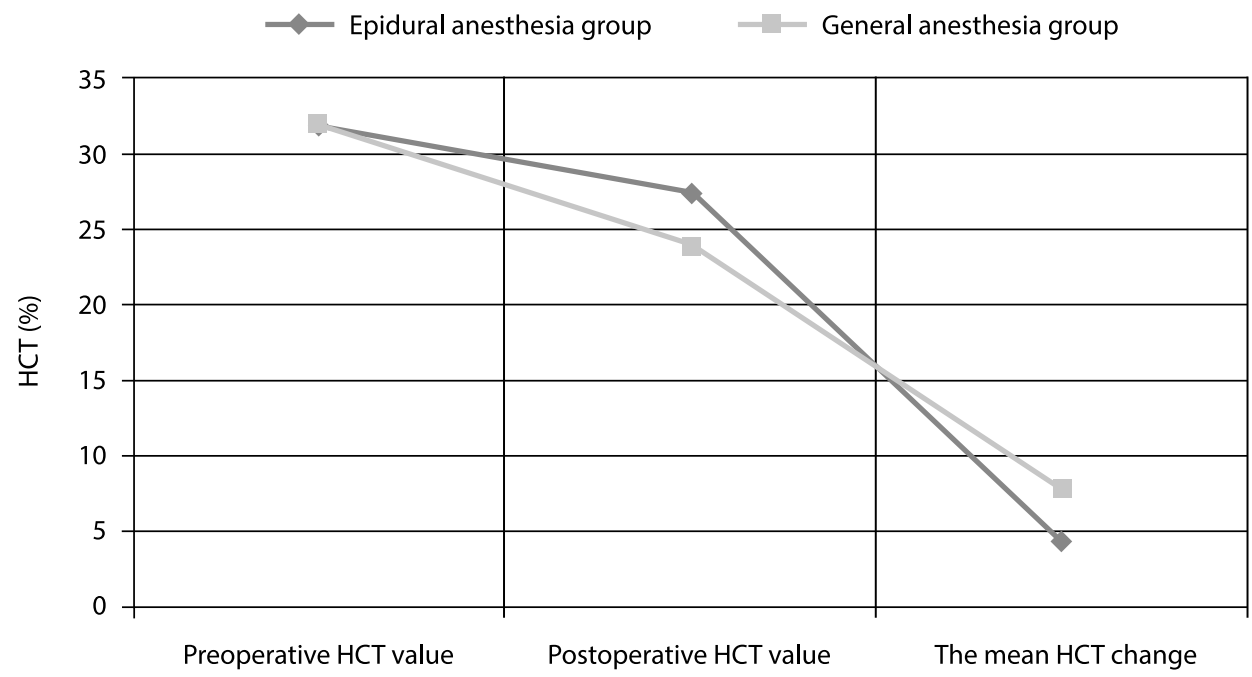

Figure 1. Preoperative, postoperative hematocrit $(\mathrm{HCT})$ level and the mean $\mathrm{HCT}$ change in the two groups

and Iran [19] , measured blood loss from the blood in the suction bottle but our study evaluated other losses plus the suction bottle using weight measurement method, this justify the increase in blood loss in this study.

In our study, the intra-operative blood transfusion rate was $19.8 \%$, similar to reports with previous studies $15.3 \%$ [18] and 24\% [20]; some studies reported no blood transfusion requirement [19], our study has myomas with larger size, uterine sizes more than 24 weeks in some patients and presence of multiple fibroids in many patients.

Maximum blood loss was $2580 \mathrm{~mL}$ in patients who underwent general anaesthesia and $1650 \mathrm{~mL}$ in patients who underwent epidural anaesthesia. Three or fewer units of RBC transfusion were required only in 11 (14.1\%) patients who underwent epidural anaesthesia, while one patient only required more than three units of transfusion. While $13(16.66 \%)$ patients undergoing general anaesthesia required three or fewer RBC transfusion units and 6 (7.7\%) required more than three units. Accordingly, transfusion of RBCs and human fibrinogen concentrate were significantly higher $(p<0.001)$ in group II (patients under general anaesthesia) compared to group I (patients under epidural anaesthesia).

On the time, there is no consensus when to start blood transfusion during myomectomy procedure, in our study transfusion was started when the calculated maximum tolerated blood loss or signs of cardiovascular instability from massive bleeding was reached. However, another study used a loss of $2000 \mathrm{ml}$ as an indication to start blood transfusion [19].
The previous studies suggest that epidural anaesthesia may be a better and safer option than general anaesthesia for surgeries with massive bleeding that need to initiate blood transfusion, as inhaled anaesthetics can cause uterine relaxation and thereby increase blood loss and increase the need for blood transfusion [21]. An earlier study reported that regional anaesthesia reduced intraoperative blood loss due to sympathetic blockade [22]. Lilker et al. [23] concluded that most patients undergoing surgeries with massive bleeding could tolerate prolonged surgery and excessive blood loss under epidural anaesthesia.

Only two patients in this study who underwent epidural anaesthesia were switched to general anaesthesia because of the hemodynamic instability caused by severe bleeding. In our study hysterectomy was the main cause of the change to general anaesthesia where hysterectomy was performed in six patients (3.8\%), four under general anaesthesia and two starting to have epidural anesthesia but switching to general anaesthesia before hysterectomy.

Several studies $[24,25]$ have shown that angiogenesis is a prerequisite for tumor growth. VEGF-C is an important factor in the development of angiogenesis, increases mitogenic and vascular permeability activity, and is specific to endothelial cells. Zhang et al. noted that there is a correlation between anaesthesia and serum VEGF-C level. They also suggest in their study that the recurrence rate of myomas and progression of postoperative leiomyomas can be reduced in patients undergoing spinal and epidural anesthesia [26].

The strengths of this study include the prospective nature, randomized design, the detailed registry of surgi- 
cal parameters, the accuracy of estimated blood loss and the use of a regression model to account for potential confounding factors related to operative blood loss. A discussion of how epidural anaesthesia affects excessive blood loss may be more clinically useful and further research is needed.

\section{CONCLUSIONS}

In women with large fibroid uterus planning for surgical removal, gynecology-anaesthesia team should be careful to choose the best anaesthetic technique, taking into account the location and the size of myoma, expected volume of blood loss, and surgical complications, for patient safety.

\section{Ethical approval}

An informed written consent was obtained from the patient for the publication.

\section{Conflict of Interest}

The authors declare no conflicts of interest.

\section{Funding}

The authors have no sources of funding to declare for this manuscript.

\section{REFERENCES}

1. Parker WH. Uterine myomas: management. Fertil Steril. 2007; 88(2): 255-271, doi: 10.1016/j.fertnstert.2007.06.044, indexed in Pubmed: 17658523.

2. Kongnyuy EJ, Wiysonge CS. Interventions to reduce haemorrhage during myomectomy for fibroids. Cochrane Database Syst Rev. 2011(11): CD005355, doi: 10.1002/14651858.CD005355.pub4, indexed in Pubmed: 22071823.

3. Rock JA, Jones HW. Te Linde's operative gynecology. Wolters Kluwer Health/Lippincott Williams \& Wilkins 2008.

4. Adesina KT, Owolabi BO, Raji HO, et al. Abdominal myomectomy: A retrospective review of determinants and outcomes of complications at the University of Ilorin Teaching Hospital, llorin, Nigeria. 2017; 29(1): 37-42, doi: 10.4314/mmj.v29i1.8, indexed in Pubmed: 28567195.

5. Omole-Ohonsi A, Ashimi OA. Non-emergency hysterectomy: why the aversion? Arch Gynecol Obstet. 2009; 280(6): 953-959, indexed in Pubmed: 19319553.

6. Kunde $K$, Cortes E, Seed $P$, et al. Evaluation of perioperative morbidity associated with single and multiple myomectomy. J Obstet Gynaecol. 2009; 29(8): 737-741, doi: 10.3109/01443610903225307, indexed in Pubmed: 19821669.

7. Balogun OR, Nwachukwu CND. Surgical findings at laparatomy for uterine fibroid in University of Ilorin Teaching Hospital .Trropical Journal of Health Sciences. 2006; 13(2): 27-30, doi: 10.4314/tjhc.v13i2.36695.

8. Ikechebelu JI, Ezeama CO, Obiechina NJA. The use of torniquet to reduce blood loss at myomectomy. The use of torniquet to reduce blood loss at myomectomy. 2010; 13(2): 13, indexed in Pubmed: 20499747.

9. Choi WS, Samman N. Risks and benefits of deliberate hypotension in anaesthesia: a systematic review. International Journal of Oral and Maxillofacial Surgery. 2008; 37(8): 687-703, doi: 10.1016/j.ijom.2008.03.011.
10. Ervens J, Marks $C$, Hechler $M$, et al. Effect of induced hypotensive anaesthesia vs isovolaemic haemodilution on blood loss and transfusion requirements in orthognathic surgery: a prospective, single-blinded, randomized, controlled clinical study. Int J Oral Maxillofac Surg. 2010; 39(12): 1168-1174, doi: 10.1016/j.ijom.2010.09.003, indexed in Pubmed: 20961738.

11. Quinn SD, Vedelago J, Kashef E, et al. Measurement of uterine fibroid volume: a comparative accuracy and validation of methods study. Eur J Obstet Gynecol Reprod Biol. 2013; 171(1): 161-165, doi: 10.1016/j. ejogrb.2013.08.036, indexed in Pubmed: 24035324.

12. Nadler SB, Hidalgo JU, Bloch TJS. Prediction of blood volume in norma human adults. Surgery. 1962; 51(2): 224-232, indexed in Pubmed: 21936146.

13. Gross JB. Estimating allowable blood losscorrected for dilution. Anesthesiology. 1983; 58(3): 277-280, doi: 10.1097/00000542-198303000-00016, indexed in Pubmed: 6829965.

14. Freeman AK, Thorne CJ, Gaston CL, et al. Hypotensive epidural anesthesia reduces blood loss in pelvic and sacral bone tumor resections. Clin Orthop Relat Res. 2017; 475(3): 634-640, doi: 10.1007/s11999-016-4858-4, indexed in Pubmed: 27172818.

15. Davids A. Myomectomy; surgical technique and results in a series of 1,150 cases. American Journal of Obstetrics and Gynecology. 1952; 63(3): 592-604, doi: 10.1016/0002-9378(52)90074-4, indexed in Pubmed: 14902973.

16. Varol N, Healey M, Tang P, et al. Ten-year review of hysterectomy morbidity and mortality: can we change direction? Aust N Z J Obstet Gynaecol. 2001;41(3): 295-302, doi: 10.1111/j.1479-828x.2001.tb01231.x, indexed in Pubmed: 11592544.

17. Feltracco P, Carollo C, Barbieri S, et al. Early respiratory complications after liver transplantation. World Journal of Gastroenterology. 2013; 19(48): 9271, doi: 10.3748/wjg.v19.i48.9271.

18. Celik H, Sapmaz E. Use of a single preoperative dose of misoprostol is efficacious for patients who undergo abdominal myomectomy. Fertility and Sterility. 2003; 79(5): 1207-1210, doi: 10.1016/s00150282(03)00076-1.

19. Niroomand N, Hajiha S, Tabrizi NM, et al. A single dose of misoprostol for reducing hemorrhage during myomectomy: a randomized clinical trial. Arch Gynecol Obstet. 2015; 292(1): 155-158, doi: 10.1007/s00404015-3617-1, indexed in Pubmed: 25600444.

20. Abdel-Hafeez M, Elnaggar A, Ali M, et al. Rectal misoprostol for myomectomy: A randomised placebo-controlled study. Australian and New Zealand Journal of Obstetrics and Gynaecology. 2015; 55(4): 363-368, doi: 10.1111/ajo.12359.

21. Bonner SM, Haynes SR, Ryall D. The anaesthetic management of Caesarean section for placenta praevia: a questionnaire survey. Anaesthesia. 2007; 50(11): 992-994, doi: 10.1111/j.1365-2044.1995.tb05938.x.

22. Chestnut DH, Dewan DM, Redick LF, et al. Anesthetic management for obstetric hysterectomy: a multi-institutional study . Anesthesiology. 1989; 70(4):607-610, doi: 10.1097/00000542-198904000-00009, indexed in Pubmed: 2648896.

23. Lilker S, Meyer R, Downey K, et al. Anesthetic considerations for placenta accreta . Int J Obstet Anesth. 2011; 20(4): 288-92, doi: 10.1016/j. ijoa.2011.06.001, indexed in Pubmed: 21840207.

24. Ciarmela P, Islam MdS, Reis FM, et al. Growth factors and myometrium: biological effects in uterine fibroid and possible clinical implications. Hum Reprod Update. 2011; 17(6): 772-790, doi: 10.1093/humupd/dmr031, indexed in Pubmed: 21788281.

25. Carmeliet $P$, Jain R. Angiogenesis in cancer and other diseases. Nature. 2000; 407(6801): 249-257, doi: 10.1038/35025220.

26. Zhang $Y, Y u$ J, Yang $F$, et al. Effect of anesthetic technique on serum vascular endothelial growth factor $C$ and prostaglandin E2 levels in women undergoing surgery for uterine leiomyomas. J Int Med Res. 2020; 48(4): 300060520918420, doi: 10.1177/0300060520918420, indexed in Pubmed: 32314939. 